\title{
Pengaruh Penambahan Abu Sekam Padi Terhadap Sifat Fisis dan Mekanis pada Mortar
}

\author{
Ahmad Munawir Siregar ${ }^{(1) *}$, Simon Sembiring, Roniyus Marjunus \\ (1) Jurusan Fisika, FMIPA,Universitas Lampung, Bandar Lampung, 35141, Indonesia \\ Email*amrmunawir@gmail.com, simon.sembiring@fmipa.unila.ac.id,roniyus.1977@fmipa.unila.ac.id
}

Diterima (26 September 2019), Direvisi (4 Nopember 2019)

\begin{abstract}
The research was carried out about the effect of adding rice husk ash to physical and mechanical properties of mortar. Mortar was moulded with three compositions of portland cement, rice husk ash, and rice stalk fiber. Rice husk ash was burned at temperature of $700{ }^{\circ} \mathrm{C}$ for 2 hours. Rice stalk fiber was mechanically sliced up to $0.8 \mathrm{~mm}$ in size. Then mortar molding and maintenance was processed for 28 days. The mortars that had reached the age of 28 days were tested according to the Indonesia National Standard (SNI) including physical properties (water absorption, density), and mechanical properties (compressive strength, modulus of elasticity, modulus of rupture). Characterization of microstructure, morphology and composition all elements on the surface of mortar were processed by using Scanning Electron Microscopy Energy Dispersive X-ray Spectroscopy (SEM-EDS). The results of research have effect of adding rice husk ash to physical and mechanical properties. Mortar with the most optimum physical and mechanical properties is mortar with a composition of 13: 2: 5. The results of the characterization using SEM-EDS shows that the surface of this compositions sample is better then other sample with its grain diameter (1.4 \pm 0.9) $\mu \mathrm{m}$. The most dominant elements in the mortar are element of $\mathrm{Ca}$ and Si which functioned as mortar binder and hardener.
\end{abstract}

Keywords: mechanical properties, mortar, physical properties, SEM-EDS.

\begin{abstract}
Abstrak. Penelitian yang dilakukan tentang pengaruh penambahan abu sekam padi terhadap sifat fisis dan mekanis mortar. Mortar dicetak dengan tiga perbandingan komposisi antara semen ordinary portland, abu sekam padi, dan serat tangkai padi. Abu sekam padi dibakar pada suhu $700{ }^{\circ} \mathrm{C}$ selama 2 jam, serat tangkai padi dirajang secara mekanis hingga berukuran $0,8 \mathrm{~mm}$, kemudian dilakukan pencetakan mortar dan perawatan selama 28 hari. Mortar yang telah mencapai usia 28 hari di uji sesuai dengan Standar Nasional Indonesia (SNI), yang meliputi sifat fisis (daya serap air, kerapatan), dan sifat mekanis (kuat tekan, kuat tarik belah, kuat lentur). Karakterisasi struktur mikro, morfologi, dan komposisi semua unsur yang ada pada permukaan mortar dilakukan menggunakan Scanning Electron Microscopy - Energy Dispersive X-ray Spectroscopy (SEM-EDS). Hasil penelitian menunjukkan adanya pengaruh penambahan abu sekam padi terhadap sifat fisis dan mekanis mortar. Mortar dengan sifat fisis dan mekanis yang paling optimum adalah mortar dengan komposisi 13:2:5. Hasil karakterisasi menggunakan SEM-EDS memperlihatkan permukaan mortar tersebut adalah yang lebih baik dengan diameter butir $(1,4 \pm 0,9) \mu \mathrm{m}$. Unsur yang paling dominan pada mortar adalah unsur $\mathrm{Ca}$ dan Si yang berfungsi sebagai pengikat dan pengeras mortar.
\end{abstract}

Kata kunci: mortar, sifat fisis, sifat mekanis, SEM-EDS.

\section{PENDAHULUAN}

Indonesia merupakan salah satu negara dengan tingkat konsumsi beras tertinggi di Asia. Data akhir tahun 2018, total konsumsi beras nasional mencapai 33,47 juta ton. Hal ini akan berdampak pada penumpukan limbah padi yang tidak diolah. Data BPS Lampung (2018) memperlihatkan luas panen padi di Provinsi Lampung periode Januari-September 2018 sebesar 336,69 ribu hektar. Dengan memperhitungkan potensi produksi sampai Desember 2018, maka luas panen tahun 2018 adalah 397,44 ribu hektar. Total produksi padi tahun 2018 sebesar 1,90 juta 
ton. Limbah padi diperkirakan mencapai 800 ribu ton. Limbah ini akan meningkat setiap tahunnya jika tidak diolah [1].

Sekam padi merupakan salah satu limbah pertanian yang belum banyak dimanfaatkan menjadi produk yang mempunyai nilai tambah [2]. Kandungan komponen kimia sekam padi pada saat pembakaran diantaranya $\mathrm{SiO}_{2}, \mathrm{CaO}, \mathrm{Na}_{2} \mathrm{O}$, $\mathrm{K}_{2} \mathrm{O}, \mathrm{Al}_{2} \mathrm{O}_{3}$, dan $\mathrm{MgO}$. Semakin tinggi suhu pembakaran, maka kadar silika murni akan semakin tinggi [3]. Agar kandungan silika tinggi, abu sekam padi dibakar selama 1-2 jam pada suhu $700{ }^{\circ} \mathrm{C}$ [4]. Abu sekam padi yang memiliki kandungan silika berfungsi sebagai filler pada mortar. Serat tangkai padi juga dapat ditambahkan sebagai bahan tambahan pada pembuatan mortar [5]. Serat tangkai padi ini merupakan limbah padi yang memiliki struktur morfologi serat yang bagus dan kandungan kimia seperti selulosa dan lignin. Kandungan serat tangkai padi ini digunakan sebagai bahan penguat pada mortar [6].

Banyaknya penggunaan semen pada pembangunan infrastruktur mengakibatkan material pembuatan semen dari alam semakin sedikit [7]. Untuk mengurangi penggunaan bahan alam, mendorong ditemukannya material-material alternatif yang dapat digunakan sebagai bahan tambahan pada semen [8]. Dalam hal ini, penambahan abu sekam padi dan serat tangkai padi pada mortar diharapkan akan menjadikan kualitas mortar yang baik [9]. Serat tangkai padi ini merupakan inovasi dan pembeda pada penelitian sebelumnya.

Faktor-faktor yang mempengaruhi kualitas mortar secara fisika adalah sifat fisis yaitu kerapatan (bulk density), daya serap air (absorption), dan sifat mekanis yaitu kuat tekan (compressive strength), kuat lentur (modulus of elasticity), dan kuat tarik belah (modulus of rupture) [10,11]. Berdasarkan faktor-faktor tersebut, pada penelitian sebelumnya belum diperoleh pengujian yang lengkap, maka dilakukanlah penelitian tentang pengaruh variasi penambahan abu sekam padi terhadap sifat fisis dan mekanis pada mortar ini.

\section{METODE PENELITIAN}

Penelitian ini menggunakan bahan dasar semen jenis Ordinary Portland Cement (OPC), abu sekam padi, serat tangkai padi, dan $\mathrm{CaCl}_{2}$. Preparasi abu sekam padi dimulai dari tahap pembersihan dengan air, dan pengeringan sekam padi di bawah sinar matahari hingga kering. Sekam padi dibakar menggunakan furnace pada suhu $700{ }^{\circ} \mathrm{C}$ selama 2 jam yang akan menghasilkan abu sekam padi dengan struktur silika amorf. Preparasi serat tangkai padi ini juga dilakukan dengan membersihkan tangkai padi hingga bersih dan kering. Tangkai padi dirajang secara mekanis sampai halus dan didapatkan serat tangkai padi berukuran $0,8 \mathrm{~mm}$.

Pembuatan sampel mortar dilakukan dengan tiga komposisi campuran antara semen : abu sekam padi : serat tangkai padi yaitu mortar A dengan komposisi 75\% : 0\% : 25\%, mortar B dengan komposisi $65 \%$ : $10 \%: 25 \%$, dan mortar $\mathrm{C}$ dengan komposisi 55\% : $20 \%$ : 25\%. Semua campuran diaduk secara merata selama 5 menit, semen yang telah dicampur akan menjadi semen komposit. Selanjutnya, semen komposit ditambahkan $\mathrm{CaCl}_{2}$ sebesar $0,5 \%$ ke dalam air, perbandingan semen komposit dengan air yaitu sebesar 1 : 0,5. Air dimasukaan ke dalam adonan semen komposit dan adonan di aduk selama 5 menit hingga merata. Setelah pengadukan selesai, adonan di cetak kemudian di keringkan selama 24 jam hingga mengeras. Cetakan di lepas dari sampel mortar yang sudah mengeras, dan sampel mortar disimpan pada suhu ruang selama 28 hari untuk dilakukan pengujian sifat fisis maupun mekanis mortar. Untuk mendukung hasil pengujian ini, karakterisasi struktur mikro, morfologi permukaan dan mengukur semua unsur yang ada pada mortar 
digunakan Scanning Electron Microscopy Energy Dispersive $X$-ray Spectroscopy (SEM-EDS).

\section{Hasil Mortar \\ HASIL DAN PEMBAHASAN}

Mortar yang dihasilkan dengan tiga variasi komposisi ini dilakukan pengujian sesuai dengan Standar Nasional Indonesia (SNI-03-0691-1993) diantaranya sifat fisis (kerapatan, daya serap), dan sifat mekanis (kuat tekan, kuat lentur, dan kuat tarik belah). Kemudian karakterisasi struktur mikro, morfologi permukaan dan mengukur semua unsur kimia pada mortar menggunakan SEM-EDS.

\section{Struktur Morfologi dan Komposisi pada Permukaan Mortar}

Pada Gambar 2 terlihat bahwa, permukaan mortar mengalami gradasi warna gelap terang. Menurut Masrukan dan Aditoiyanto (1999), semakin besar nomor atom suatu unsur maka semakin terang permukaan mortar, sehingga unsur $\mathrm{Ca}$ merupakan unsur dengan nomor atom paling tinggi dibandingkan dengan unsur
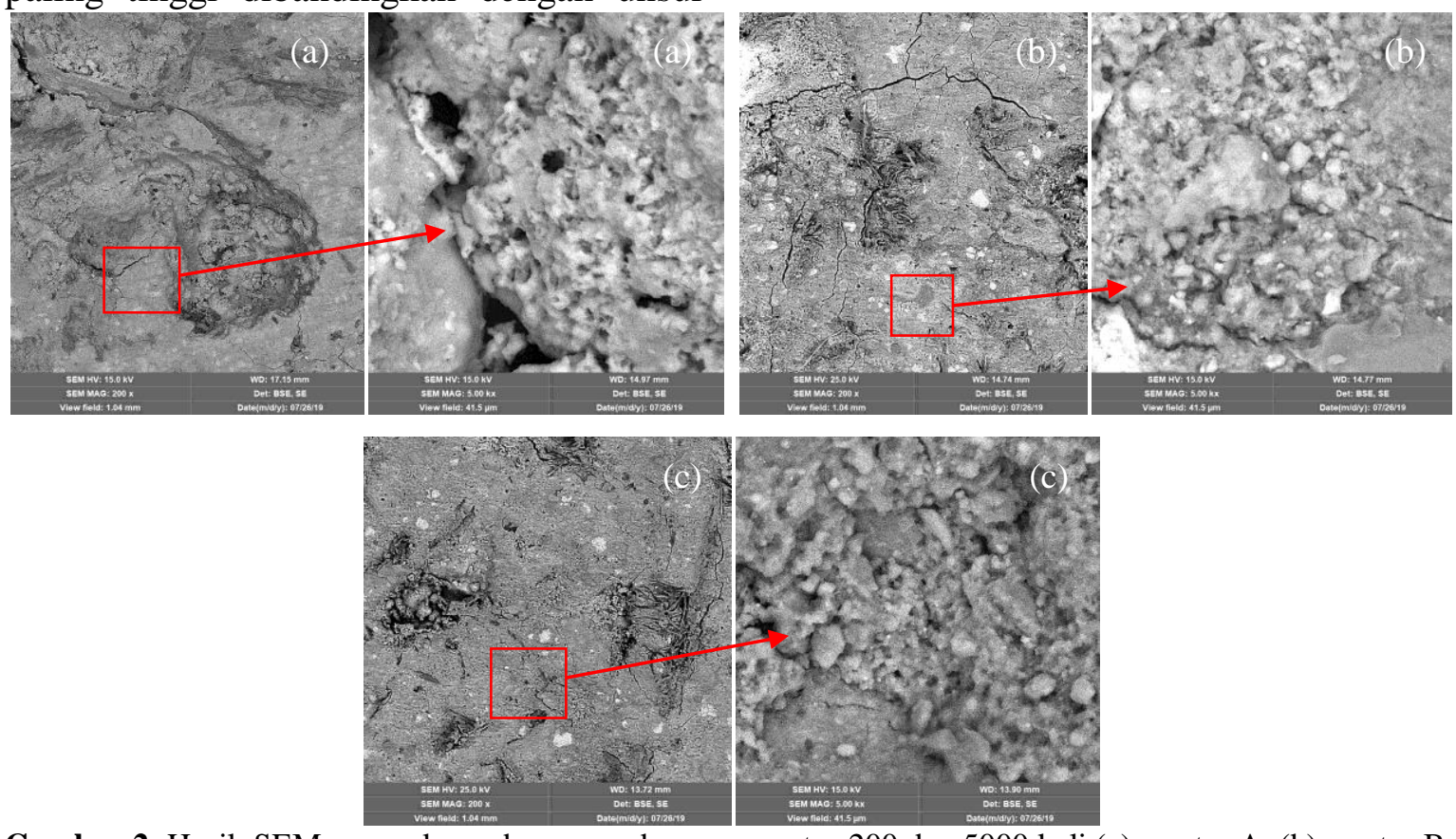

Gambar 2. Hasil SEM permukaan dengan perbesaran mortar 200 dan 5000 kali (a) mortar A, (b) mortar B, mortar B (c) mortar C.

lainnya. Kemudian, dipermukaan mortar juga terdapat butiran-butiran kecil yang merupakan proses terjadinya reaksi pengikatan antara unsur $\mathrm{H}, \mathrm{O}, \mathrm{Ca}, \mathrm{C}$, dan $\mathrm{Si}$ pada permukaan mortar. Unsur-unsur yang teridentifikasi tersebut, dimungkinkan terbentuknya senyawa $3 \mathrm{CaOSiO}_{2}, \mathrm{Ca}(\mathrm{OH})_{2}$, $\mathrm{CaCO}_{3}$, dan $\mathrm{SiO}_{2}$ yang berasal dari bahan pembuat mortar [13]

Gambar 2 (a), hasil perbesaran 200 kali menunjukkan morfologi sampel mengalami cracking (retakan) halus, terbentuknya cluster (gumpalan) dan permukaan sampel tidak homogen. Perbesaran 5000 kali, pada permukaan sampel terdapat rongga-rongga kosong (pori), mulai terbentuk butiran-butiran dengan ukuran yang tidak seragam, dan tidak memiliki grain boundary (batas butir). Unsur yang terkandung pada sampel ini dapat diketahui dengan analisis EDS. Hasil tersebut disajikan pada Tabel 1 menunjukkan bahwa, terdapat kandungan unsur $\mathrm{O}, \mathrm{Ca}, \mathrm{C}$ dan Si. Adapun kandungan unsur $\mathrm{Ca}$ pada senyawa $\mathrm{Ca}(\mathrm{OH})_{2}$ memiliki fungsi sebagai pengikat dan unsur Si pada senyawa $\mathrm{SiO}_{2}$ sebagai filler pada sampel. 

Tabel 1. Prosentase unsur hasil EDS pada setiap sampel mortar

\begin{tabular}{|c|c|c|c|c|c|}
\hline $\begin{array}{l}\text { Unsur } \\
\text { Kimia }\end{array}$ & $\begin{array}{l}\text { Nomor } \\
\text { Atom }\end{array}$ & $\begin{array}{c}\text { Energi } \\
\text { Unsur }(\mathrm{keV})\end{array}$ & $\begin{array}{c}\text { Massa Unsur } \\
\text { Sampel A (\%) }\end{array}$ & $\begin{array}{l}\text { Massa Unsur } \\
\text { Sampel B (\%) }\end{array}$ & $\begin{array}{l}\text { Massa Unsur } \\
\text { Sampel C (\%) }\end{array}$ \\
\hline $\mathrm{H}$ & 1 & - & - & - & - \\
\hline $\mathrm{O}$ & 8 & $\mathrm{~K} \alpha 0.525$ & 41,74 & 41,73 & 40,02 \\
\hline $\mathrm{Ca}$ & 20 & $\mathrm{~K} \alpha 3.690$ & 29,49 & 28,36 & 26,49 \\
\hline $\mathrm{C}$ & 6 & $\mathrm{~K} \alpha 0.277$ & 18,64 & 18,07 & 21,16 \\
\hline $\mathrm{Cl}$ & 17 & $\mathrm{~K} \alpha 2.621$ & 5,41 & 3,60 & 4,14 \\
\hline $\mathrm{Si}$ & 14 & $\mathrm{~K} \alpha 1.739$ & 2,76 & 5,92 & 5,98 \\
\hline $\mathrm{Al}$ & 13 & $\mathrm{~K} \alpha 1.486$ & 0,95 & 1,05 & 1,02 \\
\hline $\mathrm{Fe}$ & 26 & $\begin{array}{l}\mathrm{K} \alpha 6.398 \\
\mathrm{~L} \alpha 0.705\end{array}$ & 0,79 & 1,03 & 0,99 \\
\hline $\mathrm{Na}$ & 11 & $\mathrm{~K} \alpha 1.041$ & 0,22 & 0,19 & 0,21 \\
\hline \multicolumn{2}{|c|}{ Jumlah } & & 100,00 & 100,00 & 100,00 \\
\hline
\end{tabular}

Gambar 4.3 (b) dengan perbesaran 200 kali, morfologi sampel mengalami cracking yang panjang, dan permukaan sampel homogen. Kemudian perbesaran 5000 kali, permukaan sampel tidak memiliki rongga (pori), dan terbentuk butiran-butiran yang berbeda-beda. Hasil EDS sampel menunjukkan kandungan unsur $\mathrm{O}, \mathrm{Ca}$, dan $\mathrm{C}$ menurun, akibatnya morfologi sampel mengalami cracking yang panjang. Sedangkan penambahan abu sekam padi sebesar $10 \%$ memperlihatkan kandungan unsur $\mathrm{Si}$ pada Tabel 1 meningkat, sehingga sampel mortar lebih homogen dan rongga (pori) pada sampel tertutupi. Senyawa kalsium silikat hidrat $\left(3 \mathrm{CaO} .2 \mathrm{SiO}_{2} .3 \mathrm{H}_{2} \mathrm{O}\right)$ gel dan portlandite $\mathrm{Ca}(\mathrm{OH})_{2}$ ini tersebar luas pada permukaan mortar, semakin besar kandungan unsur Si, maka semakin banyak senyawa kalsium silikat hidrat yang terbentuk pada permukaan mortar [14,15].

Gambar 2 (c), pada perbesaran 200 kali juga mengalami cracking yang pendek, dan permukaan sampel terlihat homogen. Perbesaran 5000 kali, mikrostruktur sampel tampak tidak memiliki rongga (pori) dan terbentuk butiran-butiran yang tidak beraturan serta distribusinya tidak merata. Hasil EDS kandungan unsur $\mathrm{O}$, dan $\mathrm{Ca}$ menurun dibandingkan dengan sampel sebelumnya. Meningkatnya kandungan unsur C pada sampel ini memperlihatkan permukaan sampel berwarna gelap, dan penambahan abu sekam padi sebesar 20\% tidak mengindikasikan kenaikan kandungan unsur Si yang signifikan.

Dari ketiga sampel yang telah dianalis, senyawa $\mathrm{Ca}(\mathrm{OH})_{2}$ berperan sebagai pengikat, dengan menurunnya kadar $\mathrm{Ca}$ pada sampel menyebabkan cracking semakin banyak. Sedangkan senyawa $\mathrm{SiO}_{2}$ untuk mengisi rongga-rongga permukaan sampel, sehingga meningkatnya unsur Si dapat mengakibatkan permukaan mortar lebih rapat dan homogen.

Proses terjadinya reaksi senyawa, ditunjukkan pada Persamaan 1 dan 2 berikut.

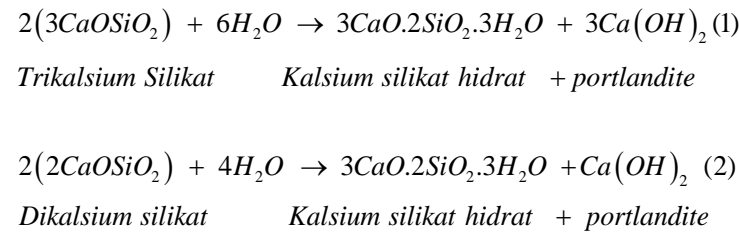

Ketika bahan bereaksi dengan air, masing-masing unsur mengalami hidrasi (pengikatan), senyawa yang terbentuk adalah trikalsium silikat, terbentuk pada usia 7 hari, yang disebut dengan kekuatan awal (Persamaan 1). Produk dari hasil hidrasi selanjutnya, terbentuk dikasium silikat yang disebut dengan hardening (pengerasan) hingga mencapai pada usia 28 hari (Persamaan 2). Proses reaksi ini yang mengakibatkan mortar menjadi keras dan kuat [16]. 


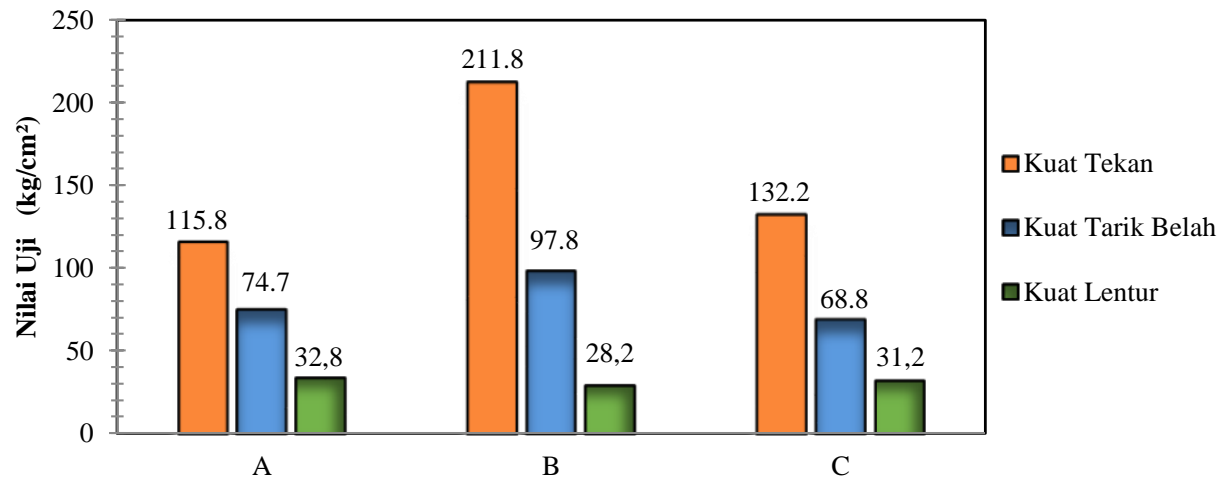

Kode Sampel

Gambar 1. Grafik pengujian sifat mekanis

\section{Sifat Fisis Mortar}

Sifat fisis dan mekanis mortar ini memiliki hubungan terhadap struktur morfologi dan komposisi permukaan sampel. Pengujian sifat fisis dilakukan untuk mengetahui daya serap air pada sampel ketika direndam dalam air selama 28 hari. Hasil uji kerapatan (bulk density) terdapat anomali nilai kerapatan. Nilai kerapatan sampel A sebesar 1,37 gram $/ \mathrm{cm}^{3}$, sampel B sebesar 1,56 $\mathrm{gram} / \mathrm{cm}^{3}$, dan sampel C sebesar $1,28 \mathrm{gram} / \mathrm{cm}^{3}$, penyebab anomali ini, diakibatkan oleh sifat silika berbentuk amorf yang memiliki tingkat kejenuhan untuk menyerap air pada saat proses pencetakan hingga perendaman sampel selama 28 hari. Silika abu sekam padi yang disintering pada suhu $700^{\circ} \mathrm{C}$ juga cenderung memiliki daya serap air yang lebih kecil, sehingga dengan penambahan abu sekam padi yang berlebihan akan mengakibatkan penyerapan lebih sedikit dan massa sampel juga lebih ringan [17]. Dengan demikian, penambahan abu sekam padi yang paling optimal untuk mendapatkan kerapatan yang baik dalam penelitian ini adalah mortar B sebesar $10 \%$

Hasil pengujian penyerapan air (absorption) yang paling tinggi adalah sampel A sebesar 4,81\%. Sampel B sebesar $4,39 \%$, sedangkan tingkat penyerapan paling rendah adalah sampel $\mathrm{C}$ sebesar $3,74 \%$. Semakin besar penambahan abu sekam padi pada sampel, maka daya serap sampel terhadap air akan semakin kecil.

\section{Sifat Mekanis Mortar}

Pengujian sifat mekanis pada sampel ini dilakukan tanpa perendaman. Hasil pengujian kuat tekan (compressive strength), kuat tarik belah (modulus of rupture), dan kuat lentur (modulus of elasticity) ditampilkan dalam bentuk grafik pada Gambar 1.

Sifat mekanis yang paling optimum adalah pada sampel mortar B dengan penambahan abu sekam padi sebesar $10 \%$. Sampel mortar B memiliki nilai kuat tekan sebesar $211,8 \mathrm{~kg} / \mathrm{cm}^{2}$, nilai kuat tarik belah sebesar $97,8 \mathrm{~kg} / \mathrm{cm}^{2}$, dan nilai kuat lentur sebesar $28,2 \mathrm{~kg} / \mathrm{cm}^{2}$. Sifat mekanis sampel mortar B ini lebih baik dibandingkan dengan sampel mortar A dan C. Sampel mortar B ini memiliki pengikatan dan pengerasan yang optimun, karena mortar tanpa penambahan abu sekam padi dan penambahan abu sekam padi secara berlebihan akan mengakibatkan senyawa utama $\mathrm{SiO}_{2}$ dan $\mathrm{CaCO}_{3}$ pada bahan tidak sebanding, sehingga proses pengikatan dan pengerasan senyawa kalsium silikat hidrat akan cenderung menurun. 
Sampel dengan penambahan abu sekam padi yang berlebihan juga dapat mengakibatkan sampel lebih mudah patah, karena pori-pori pada permukaan sampel lebih kecil dan menimbulkan daya serap air yang lebih sedikit. Sebaliknya sampel dengan tanpa penambahan abu sekam padi, akan mengakibatkan sulitnya terjadi proses pengikatan dan pengerasan, karena penyerapan air yang cenderung lebih banyak [18].

\section{KESIMPULAN}

Bedasarkan hasil penelitian yang telah dilakukan, dapat diambil kesimpulan bahwa penambahan abu sekam padi dapat meningkatkan sifat fisis dan mekanis mortar. Hasil pengujian yang paling optimum pada penelitian ini adalah sampel B dengan komposisi $13: 2: 5$, ditinjau dari sifat fisis dan mekanis maupun hasil karakterisasi SEM-EDS. Unsur Si dan $\mathrm{Ca}$ pada sampel mortar merupakan faktor yang mempengaruhi pengujian sifat fisis (daya serap, kerapatan) dan mekanis (kuat tekan, kuat taik belah, dan kuat lentur) pada mortar.

\section{DAFTAR PUSTAKA}

[1] Kementan RI, "Kementerian Pertanian Republik Indonesia," 2019. [Online]. Available: www.pertanian. go.id. [Accessed: 25-Jan-2019].

[2] T. Ningsih, R. Chairunnisa, and S. Miskah, "Pemanfaatan Bahan Additive Abu Sekam Padi pada Semen Portland PT. Semen Baturaja (Persero)," Jur. Tek. Kim. Fak. Tek. Univ. Sriwij., vol. 18, no. 4, pp. 5967, 2012.

[3] S. and P. K.-K. Sembiring, "Pengaruh suhu sintering terhadap karakteristik termal dan mikrostruktur silika sekam padi," $J$. Sains MIPA, vol. 13, no. 3, pp. 233239, 2007.
[4] N. Zemke and E. Woods, "Rice Husk Ash," J. Calif. Polytecnic State Univ., pp. 1-12, 2009.

[5] M. A. Mirza. Olivia, "Kuat Tekan Mortar OPC Abu Sekam Padi Pada Suhu Tinggi," J. Online Mhs. Fak. Tek., vol. 4, no. 1-5, p. 1, 2017.

[6] M. Ghofrani, K. N. Mokaram, A. Ashori, and J. Torkaman, "Fibercement composite using rice stalk fiber and rice husk ash: Mechanical and physical properties," J. Compos. Mater., vol. 49, no. 26, pp. 33173322, 2015.

[7] A. E. Sutrisno and D. Kartikasari, "Pengaruh Penambahan Abu Jerami Padi Terhadap Kuat Tekan Beton," $J$. CIVILA, vol. 2, no. 2, pp. 63-70, 2017.

[8] N. S. Gunawan, Purnawan, Wibowo, "Pengaruh Penambahan Serat Aluminium Pada Beton Ringan Dengan Teknologi Foam Terhadap Kuat Tekan , Kuat Tarik Foam Terhadap Kuat Tekan , Kuat Tarik," e-Jurnal Matriks Tek. Sipil, vol. 2, no. 2, p. ISSN 2354-8630. 213-220, 2014.

[9] S. Mulyati, D. Dahlan, and E. Adril, "Pengaruh persen massa hasil pembakaran Serbuk Kayu Dan Ampas Tebu Pada Mortar Terhadap Sifat Mekanik Dan Sifat Fisisnya," $J$. Ilmu Fis., vol. 4, no. 1, pp. 31-39, 2012.

[10] H. Chao-Lung, B. Le Anh-Tuan, and C. Chun-Tsun, "Effect of rice husk ash on the strength and durability characteristics of concrete," Constr. Build. Mater., vol. 25, no. 9, pp. 3768-3772, 2011.

[11] T. K. Sitorus, "Pengaruh Penambahan Silika Amorf Dari Sekam Padi Terhadap Sifat Mekanis Dan Sifat Fisis Mortar," Skripsi Dep. Fis. FMIPA USU, p. Medan, 2009.

[12] W. Masrukan and Aditoiyanto, "Pemeriksaan Mikrosruktur dan 
Analisis Unsur A1MgSi1

Menggunakan Scanning Electron

Microscope (SEM)-EDS," in

Prosiding Seminar Nasional

Hamburan Neutron dan Sinar X Ke-

2, 1999, p. ISSN 1410-7686.

[13] N. Narayanan and K. Ramamurthy, "Microstructural investigations on aerated concrete," J. Cem. Concr. Res., vol. 30, pp. 457-464, 2000.

[14] D. Chopra, R. Siddique, and Kunal, "Strength, permeability and microstructure of self-compacting concrete containing rice husk ash," Biosyst. Eng., vol. 130, pp. 72-80, 2015.

[15] M. Jamil, M. N. N. Khan, M. R. Karim, A. B. M. A. Kaish, and M. F. M. Zain, "Physical and chemical contributions of Rice Husk Ash on the properties of mortar," Constr. Build. Mater., vol. 128, pp. 185-198, 2016.

[16] R. Simanjuntak, "Pengaruh pencampuran semen pada tanah lempung terhadap kekuatan geserpuncak dan geser sisa," J. Sains dan Teknol. EMAS, vol. 17. No 3, pp. 254-259, 2007.

[17] H. dan A. L. N. Fahmi, "Analisa Daya Serap Silika Gel Berbahan Dasar Abu Sekam Padi," J. Ipteks Terap., vol. 3, pp. 176-182, 2016.

[18] K. Sinulingga, "Pengaruh penambahan abu sekam padi dan abu boyler kelapa sawit terhadap efisiensi penggunaan semen pada kontruksi beton," J. Saintika, vol. 14, no. 1, pp. 54-63, 2014. 
Siregar, dkk : Pengaruh Penambahan Abu Sekam Padi Terhadap Sifat Fisis dan Mekanis pada Mortar 